\title{
Aplicação da engenharia de materiais focado no aumento da vida útil de componentes industriais
}

Application of Materials Engineering focused on increasing the service life of industrial components

Aplicación de ingeniería de materiales enfocada en aumentar la vida útil de los componentes industriales

Leonardo Pereira de Andrade ORCID: https://orcid.org/0000-0003-3930-2746 Universidad Internacional Iberoamericana, México E-mail: leoprofessor25@gmail.com

Adriana Ferreira da Silva

ORCID: https://orcid.org/0000-0002-6615-7938

Universidade Autônoma de Yucatán, México E-mail: adriana.dasilva@correo.uady.mx

\begin{abstract}
Resumo
Os componentes empregados atualmente nos processos industriais vêm sofrendo desgaste excessivo devido ao aumento da utilização, à baixa qualidade de produtos e/ou serviços de manutenção e operação, à falta de expertise da mão de obra empregada nos processos produtivos, ao decréscimo de reservas com minerais livres de contaminantes e às propriedades mecânicas dos metais. Frente a este cenário é notório que dentro das indústrias existem grandes perdas, sejam elas financeiras, de produtividade, de segurança e que acarretam retrabalhos e na insatisfação dos profissionais devido à baixa performance de máquinas e equipamentos. A aplicação da engenharia de materiais, por meio de estudos diversos, desenvolveu técnicas para a utilização de polímeros visando aumentar a vida útil de componentes, tendo como consequência subconjuntos e/ou máquinas e equipamentos que corroboram para com a mudança deste cenário. A constante necessidade da redução de custos no mercado industrial a partir de trocas, quebras, reformas e acidentes devido ao desgaste prematuro de componentes tornou-se uma opção viável para as organizações, sendo essa a relevância social deste trabalho. Dessa forma, propõe-se como problemática de pesquisa a seguinte questão: Como aplicar a Engenharia de Materiais focado no aumento da vida útil de componentes industriais?
\end{abstract}

Palavras-chave: Engenharia; Engenharia de materiais; Polímeros; Ciclo de vida; Subconjuntos.

\begin{abstract}
The components that are currently being employed in industrial processes have been subjected to excessive wear due to: their increased usage, the low quality of these products and / or the maintenance and operation services that are provided them, the lack of expertise of the labor employed in the production processes, the decrease in reserves having minerals that are free of contaminants, and the mechanical properties of the metals that are contained in these components. In light of the above, it is clear that, within industrial sectors, substantial losses exist, be they in terms of cost, productivity, safety or even those losses that arise from the work having to be redone or from the dissatisfaction among the personnel due to the substandard performance of the machines and equipment that they must use. The application of materials engineering, through various studies, has developed techniques for the use of polymers in order to increase the service life of these components, resulting in the emergence of subassemblies and / or machines and equipment that are fundamental to this paradigm shift. The ever-present need to reduce costs in the industrial market, whether it be from replacement, breakdowns, refurbishment and accidents due to the premature wear of components, has become a feasible option for many organizations, and, in sum, summarizes the social relevance of this research. Thusly, the following question is being put forth as a research hypothesis: How can Materials Engineering that is focused on increasing the service life of industrial components be applied?

Keywords: Engineering; Materials engineering; Polymers; Life-cycle; Subassemblies.
\end{abstract}

\section{Resumen}

Los componentes que se utilizan actualmente en los procesos industriales han venido sufriendo un desgaste excesivo debido al mayor uso, la baja calidad de los productos y/o servicios de mantenimiento y funcionamiento, la falta de 
mano de obra calificada empleada en los procesos productivos, la disminución de las reservas con minerales libre de contaminantes y las propiedades mecánicas de los metales. Ante este escenario, es evidente que dentro de las industrias existen grandes pérdidas, ya sean económicas, de productividad, de seguridad y que provocan retrabajos y el descontento de los profesionales por el bajo rendimiento de las máquinas y equipos. La aplicación de la ingeniería de materiales, a través de diversos estudios, ha desarrollado técnicas de uso de polímeros con el objetivo de incrementar la vida útil de los componentes, teniendo como consecuencia, subconjuntos y/o máquinas y equipos que se corroboran con el cambio de este escenario. La constante necesidad de reducir costos en el mercado industrial por cambios, roturas, renovaciones y accidentes por desgaste prematuro de los componentes se ha convertido en una opción viable para las organizaciones, siendo ésta la relevancia social de este trabajo. De este modo, se plantea como problema de investigación la siguiente pregunta: ¿Cómo aplicar la Ingeniería de Materiales centrada en el incremento de la vida útil de los componentes industriales?

Palabras clave: Ingeniería; Ingeniería de materiales, Polímeros, Ciclo de vida, Subconjuntos.

\section{Introdução}

Para Callister Júnior \& Rethwisch (2016) o projeto de um componente ou estrutura exige, com frequência, que sejam minimizadas as possibilidades de falhas. Nesse contexto é importante compreender a mecânica dos vários tipos de falhas além dos processos que podem ser empregados para preveni-las. A falha de materiais de engenharia é, quase sempre, um evento indesejável por várias razões, as quais incluem vidas humanas que são colocadas em risco, perdas econômicas bem como pode haver certa interferência na disponibilidade de produtos e serviços/equipamentos. Os componentes empregados atualmente nos processos industriais vêm sofrendo um desgaste excessivo devido ao aumento da utilização, à baixa qualidade de produtos e ou serviços de manutenção e operação, à falta de expertise da mão de obra empregada nos processos produtivos, ao decréscimo de reservas com minerais livres de contaminantes e às propriedades mecânicas dos metais. Frente a este cenário é notório que, dentro das indústrias, existem grandes perdas, sejam elas mesmas financeiras, de produtividade, de segurança ou ainda há aquelas relacionadas aos retrabalhos e à insatisfação dos profissionais devido à baixa performance de máquinas e equipamentos. A aplicação da engenharia de materiais ganhou expressividade a partir de estudos que propuseram técnicas relacionadas à utilização de polímeros com intuito de aumentar a vida útil de componentes, tendo como exemplos de aplicações os subconjuntos e/ou máquinas e equipamentos dentro de um processo produtivo.

Durante a realização deste estudo foi possível acompanhar trabalhos de engenharia e desenvolvimento de materiais em plantas de mineração no Brasil, Chile e Peru, visando avaliar o uso dos polímeros para aumentar a vida útil de componentes industriais. Variáveis como segurança nas operações, oxidação, corrosão, desgaste, dureza, ciclo de vida, tempo médio entre falhas, disponibilidade física do ativo e ganhos financeiros foram monitorados. Os resultados mostram que este é um caminho a ser seguido e foram identificadas empresas e instituições que já estão com departamentos de pesquisa focados no tema. É importante ressaltar que a segurança das operações vem sempre em primeiro lugar, e existe uma correlação direta, pois quanto menos falhas, maior é a vida útil e menores são os riscos de acidentes, sejam pela falha em si ou pelas ações para corrigi-las. Para Kepner e Tregoe (1997), é feita uma abordagem diferenciada e inovadora sobre como tratar as falhas e como, a partir de diagnósticos de alto nível, é possível retroalimentar os processos e melhorar as condições de materiais e serviços, assim, "para estabelecer ações que possam evitar ou reduzir as chances de um problema potencial, é necessário antes saber qual é a causa provável do problema. Se esta não for removida, há grandes chances de que o problema aconteça novamente".

Em recente matéria da revista Brasil Mineral (fevereiro 21) foi abordado o tema investimentos no setor de mineração. Onde foram investidos US\$ 8,3 bilhões em 2020. Diante deste cenário, este estudo procurou fazer uma abordagem acerca de como aplicar a engenharia de materiais focado no aumento da vida útil de componentes industriais, tendo como objetivo geral contribuir para uma maior clarificação na utilização de polímeros em subconjuntos industriais, visto o aumento da vida útil, redução do número de falhas e aumento de confiabilidade. 


\section{Metodologia}

O projeto teve início com a pesquisa de referências bibliográficas existentes sobre o assunto abordado, assim como com a elaboração do estado da arte sobre o tema da tese. Esse trabalho inicial foi fundamental para comprovar a originalidade da proposta de estudo. Ele caracteriza-se como uma pesquisa de campo, pois parte-se de uma situação realista, em que uma ou mais variáveis independentes são manipuladas pelo pesquisador em condições tão controladas quanto permitir o ambiente natural. Quanto ao foco a pesquisa caracteriza-se como misto, visto o estudo ter abordagens qualitativas e quantitativas. O projeto de pesquisa foi realizado em uma empresa de mineração do Brasil e visitas técnicas a uma mineradora no Chile e outra no Peru. Os ensaios práticos foram realizados no circuito dos moinhos de bolas, bombas de recirculação de água para o equipamento. A justificativa para a escolha deste equipamento baseou-se no perfil de perdas, complexidade de manutenção, os riscos de segurança nas operações e manutenções e os altos custos envolvidos tanto para a aquisição, mantenabilidade e restabelecimento das condições originais quando necessário. Cabe ressaltar também a necessidade de redução de custos no mercado industrial com trocas, quebras, reformas e acidentes devido ao desgaste prematuro de componentes deste equipamento. A pesquisa em questão também é caracterizada como experimental. Para Sampiere et Al, 2003:

"Experimento é um estudo de pesquisa no qual se manipulam deliberadamente uma ou mais variáveis independentes (supostas causas) para analisar as consequências dessa manipulação sobre uma mais variáveis dependentes (supostos efeitos), dentro de uma situação de controle para o pesquisador".

Como população e amostra acerca do estudo temos uma planta de beneficiamento de minério de ferro localizada no Brasil onde os ensaios iniciaram a partir da etapa de moagem primária e recirculação de água. A seleção do equipamento para teste de aplicação dos polímeros (amostra) se deu de acordo com o perfil de perdas, maiores investimentos, dificuldade de manutenção e grande tempo para intervenções. Pode-se citar, também, o baixo ciclo de vida principalmente a partir da primeira reforma. Os ensaios práticos foram nos moinhos de bolas. Equipamento este que faz parte da etapa de moagem primária.

As variáveis da pesquisa, limitado aos dados e acesso a cada uma delas, são discorridas abaixo e conceituadas segundo Callister Júnior e Rethwisch (2016):

Oxidação - variável controlada e analisada (independente / qualitativa / politômica). A oxidação pode ser considerada como o início do processo de degradação do metal e deve ser tratada logo que surge, para não dar origem à corrosão e à ferrugem.

Corrosão - variável controlada e analisada (independente / qualitativa / politômica). A corrosão é definida como o ataque destrutivo e não intencional de um metal; esse ataque é eletroquímico e começa normalmente na superfície.

Desgaste - variável controlada e analisada (independente / qualitativa / politômica). Denomina-se desgaste à perda progressiva de substância da superfície de um corpo sólido, causado por ação mecânica, isto é, por contato e movimento relativo de um contra corpo sólido, líquido ou gasoso. O desgaste resulta em pequenas partículas soltas (partículas de desgaste) e em modificações no material e na geometria da camada de superfície.

Dureza - controlado e analisado (independente / qualitativa / politômica). Propriedade de um material que permite a ele resistir à deformação plástica (permanente), usualmente por penetração. O termo dureza também pode ser associado à resistência à flexão, risco, abrasão ou corte.

Vida útil - controlado e analisado (dependente / quantitativo / contínuo). Entende-se por vida útil de um ativo o período iniciado no momento de sua aquisição (entrada em operação), duração estimada de tempo (meses ou anos) que possa cumprir corretamente a função técnica para o qual foi concebido, e durante o qual ele realiza um trabalho com rentabilidade e dentro das especificações para o qual foi adquirido. Conforme preceitos de Masters (1986), resumindo, "Dez Mandamentos" 
definem a vida útil dos componentes industriais, sendo eles: definir explicitamente o problema antes de tentar resolvê-lo; Definir a vida útil de tal forma que a) possa ser medida (quantitativamente) e b) possa estar relacionada com o desempenho em serviço; Estar aberto a novas abordagens e métodos, em vez de aceitar cegamente os tradicionais; Usar procedimentos simples e sistemáticos tendo por base a lógica, senso comum e material científico; Estar ciente de que, dados qualitativos de ensaios de envelhecimento acelerado não sistemáticos podem conduzir a conclusões erradas; "Reconhecer que é impossível simular em laboratório todas as condições verificadas em serviço, mas também não é necessário fazê-lo; Garantir que os processos de degradação induzidos por ensaios de envelhecimento acelerado são os mesmos que os verificados em serviço; Medir os fatores de degradação; Ser cauteloso em relação às correlações; Reconhecer que, usando procedimentos quantitativos sistemáticos, podem ser desenvolvidos ensaios de envelhecimento acelerado válidos.

Tempo médio entre falhas - controlado e analisado (dependente, quantitativo, contínuo). Quando falamos do tempo médio entre falhas, ou MTBF, estamos nos referindo a média de tempo que uma falha ocorreu até a próxima falha ocorrer novamente. É um termo em inglês que significa Mean Time Between Failures.

Disponibilidade física do ativo - analisado (dependente, quantitativo, contínuo). É o tempo que a máquina ou equipamento está disponível para funcionar, conforme o programado. Este valor é o maior objetivo da gestão de manutenção. Quanto maior este valor, melhor.

Ganhos financeiros - analisado (dependente /quantitativo/contínuo). Após a aplicação de técnicas, métodos e produtos focados no aumento da vida útil dos componentes industriais é será possível medir os ganhos financeiros auferidos com um prolongamento de vida útil e com um aumento do tempo médio entre falhas e com o aumento da disponibilidade do ativo.

A coleta de dados foi por meio da utilização de medições em campo a partir de equipamentos, técnicas e sistemas sofisticados de diagnóstico de variáveis como oxidação, corrosão, desgaste e dureza. Técnicas de medição preditiva também foram empregadas para avaliação dos resultados e monitoramento em tempo real da performance dos equipamentos. Os ensaios não destrutivos, são técnicas utilizadas na inspeção de materiais e equipamentos sem danificá-los, sendo executados nas etapas de fabricação, construção, montagem e manutenção. Constituem uma das principais ferramentas do controle da qualidade de materiais e produtos, contribuindo para garantir a qualidade, reduzir os custos e aumentar a confiabilidade da inspeção. São largamente utilizadas nos setores petróleo/petroquímico, químico, aeronáutico, aeroespacial, siderúrgico, mineração, naval, eletromecânico, papel e celulose, entre outros. Contribuem para a qualidade dos bens e serviços, redução de custo, preservação da vida e do meio ambiente, sendo fator de competitividade para as empresas que os utilizam; Radiografia, Gamagrafia e Radioscopia; Inspeção visual; Ultrassom; Líquido Penetrante; Termografia; Elevação de Temperatura etc.

A análise dos dados foi feita a partir dos dados coletados em campo por meio dos equipamentos que fazem parte da amostra. A aplicação dos polímeros foi monitorada no formato de observação experimental e pesquisa participante. Para o caso em questão fez-se necessário analisar os dados de forma comparativa com resultados anteriores que foram coletados a partir de dados secundários. Os resultados do monitoramento foram os dados primários coletados pelo pesquisador. O sistema de gerenciamento de informações de processos, o sistema de execução da manufatura, o sistema de gerenciamento de informações de laboratório e a reconciliação e validação de dados foram utilizados para coletar informações de forma a validar os números referentes a ciclo de vida, tempo médio entre falhas e a disponibilidade física dos equipamentos.

\section{Resultados}

Dentro do propósito da pesquisa foram feitos os testes de aplicação de polímeros nas bombas de água dos circuitos de moagem e remoagem, conforme anteriormente descritos. A seguir será feito uma abordagem passo a passo de como o trabalho foi realizado e posteriormente os resultados alcançados. Existiam trocas constantes de bombas de água recuperada da usina 
devido a desgaste prematuro. Desgaste do rotor e seus anéis responsáveis por pressurização da câmara e consequentemente a perda de rendimento (pressão e vazão). São 05 bombas de água no circuito de água recuperada da Usina responsáveis por alimentação, por exemplo, dos moinhos de bolas. As bombas de água foram dimensionadas para manutenções semestrais e anuais. Para cada troca demanda recursos como guindaste, 04 mecânicos e 01 soldador, conjunto de oxicorte, caminhão munck além de seis horas de parada do equipamento. As trocas das bombas estavam acontecendo em média a cada 03 meses, onde ocorriam impactos na redução de taxa da usina, no aumento de manutenções corretivas, desgaste, oxidação e redução do ciclo de vida dos componentes, fadiga dos colaboradores, exposição aos riscos de içamento de cargas e áreas agressivas (algumas das corretivas estendiam pelo horário noturno). A disponibilidade física do equipamento também era afetada. No período amostrado de 4 meses foram identificadas 09 trocas de bombas. As figuras a seguir representam o local onde ocorria a captação de água e as condições em que as bombas se encontravam frente as situações listadas anteriormente.

Figura 1. Reservatório de água recuperada da usina

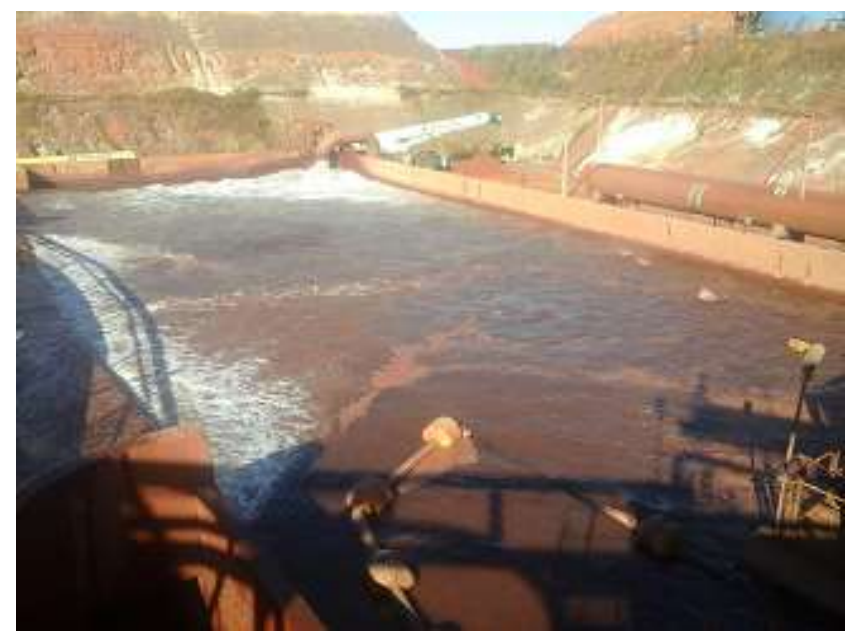

Fonte: Autores.

Figura 2. Situação das bombas de água recuperada.
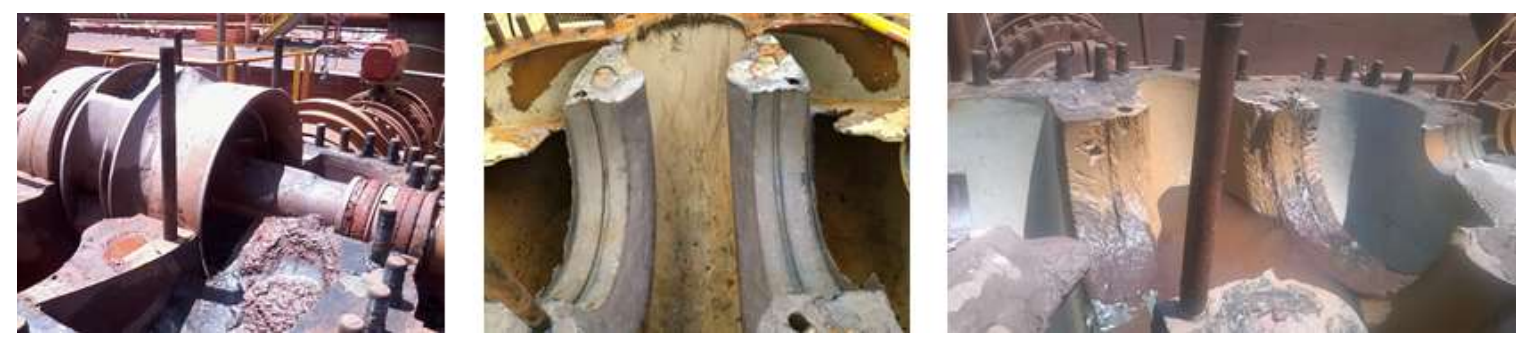

Fonte: Autores.

Frente a complexidade do problema é válido abordar alguns pontos críticos que envolvem esta tarefa, sendo eles:

- As bombas sofrem ação da alta percentagem de sólidos que promovem o desgaste acentuado;

- O desgaste interno da carcaça faz com que haja o desbalanceamento do conjunto girante. Consequentemente há quebras de rolamentos e/ou eixos;

- Com o acentuado desgaste do conjunto há a tendência de quebra podendo ocorrer perdas materiais significativas (desde o conjunto até a bomba por completo);

- Situação crítica do assento dos anéis de desgaste da carcaça no interior da bomba; 
- Algumas corretivas aconteciam em finais de horários se estendendo para o período noturno, ocasionando cansaço, fadiga dos colaboradores;

- Alocação de recursos auxiliares fora de programação (guindaste/ munck);

- Bombas com quebras constantes impedindo de termos conjuntos sobressalentes reservas. Necessidade de transportar para oficina central do site;

- Oficina de Subconjuntos tendo que atender corretivamente montagem/ recuperação de carcaças.

Junto a equipe técnica da manutenção de usina e fornecedores parceiros foram iniciados trabalhos visando solucionar o problema e depois de vários testes chegou-se a uma condição extremamente satisfatória como descrito a seguir. O problema das bombas foi resolvido a partir de estudos técnicos focados no uso de polímeros que aumentassem a vida útil dos componentes das bombas e implementação de outras melhorias visando o conjunto como um todo. Seguem os resultados auferidos:

Uso de resinas/ soldas nos pontos críticos

Figura 3. Uso de polímeros nos pontos críticos das bombas.

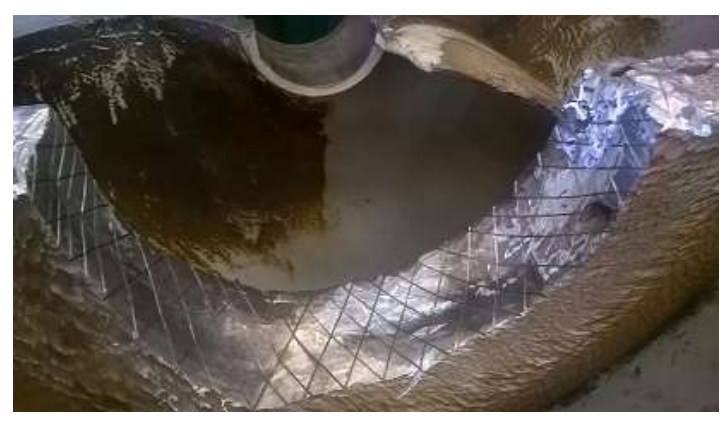

Fonte: Autores.

Aplicação de material cerâmico a base de Titânio nos anéis de desgaste da carcaça da bomba.

Figura 4. Uso de Polímeros nos Pontos Críticos das Bombas.
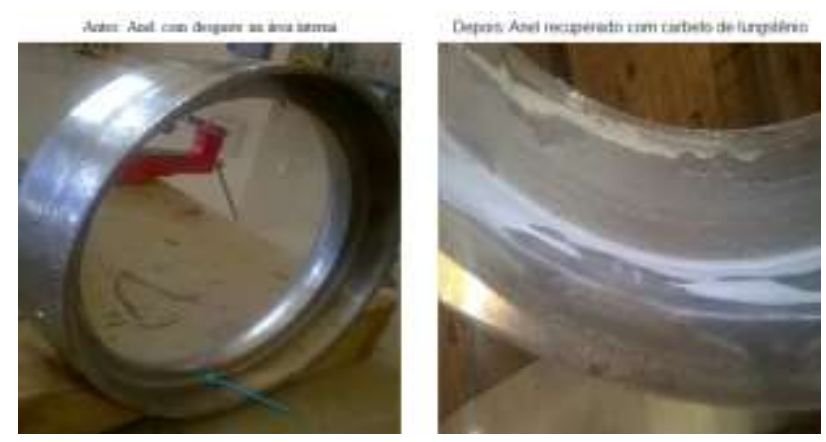

Fonte: Autores.

Aplicação de carbeto de tungstênio através do processo hipersônico (HVOF) nas buchas de desgaste, teve como objetivo o aumento da dureza de 30 para $50 \mathrm{Hrc}$. 
Research, Society and Development, v. 10, n. 6, e36810615943, 2021

(CC BY 4.0) | ISSN 2525-3409 | DOI: http://dx.doi.org/10.33448/rsd-v10i6.15943

Figura 5. Uso de Polímeros nos Pontos Críticos das Bombas.
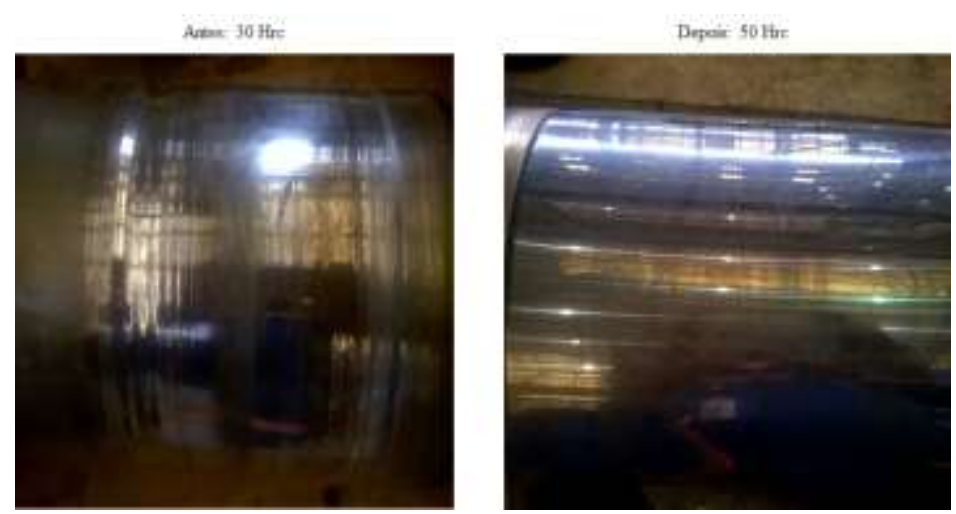

Fonte: Autores.

Alteração no sistema de vedação dos mancais com adaptação de anel defletor e retentores nos mancais, evitando a contaminação dos rolamentos com água.

Figura 6. Melhorias no sistema de vedação das bombas.
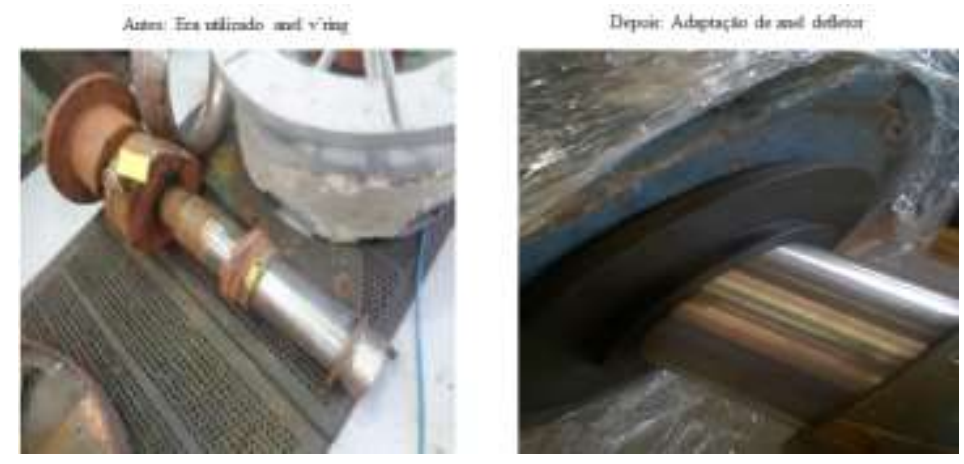

Fonte: Autores.

Montagem do conjunto rotativo na carcaça.

Figura 7. Foto bomba em processo de montagem e montada.

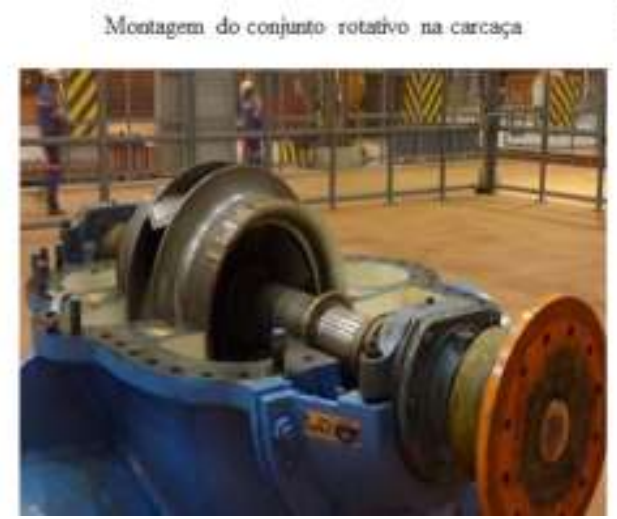

Boenbs montada com apbicaçăo dos polimeros e methorias de vedaçōes

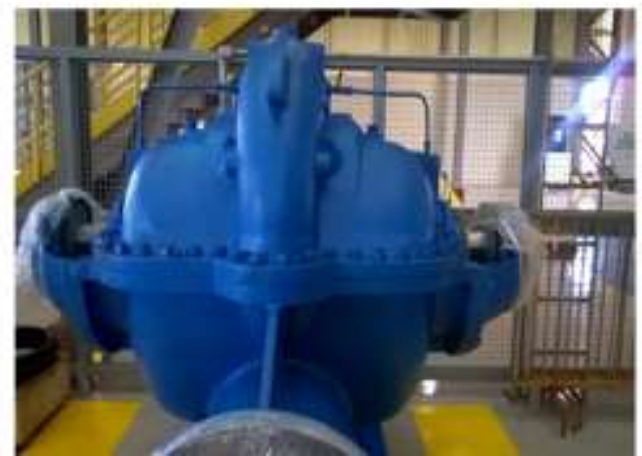

Fonte: Autores. 
Cada revisão da bomba trocada custava em média R $\$ 90.200,00$. A troca das 09 bombas resultaram num gasto aproximado de $\mathrm{R} \$ 811.800,00$ no espaço de 04 meses. Após revestir com polímero as carcaças e adequado os materiais de desgaste e vedações no intervalo de um ano foram trocadas apenas 04 bombas, numa economia aproximada de R\$1.803.640,00. O ganho de produção com o aumento da disponibilidade dos equipamentos não foi calculado, mas representa um impacto extremamente relevante para o processo produtivo e EBITDA da organização. Com a redução do número de trocas de bombas os ganhos a seguir também podem ser contabilizados:

- Redução do tempo de exposição dos colaboradores a riscos de trabalhos com içamentos de cargas, fadiga, esforços constantes;

- Eliminação da redução de taxas da usina (geralmente de 2800 para 1900 t/h).

- As bombas pararam de sofrer ação da alta percentagem de sólidos que promovem o desgaste acentuado;

- Considerável redução do desgaste interno da carcaça;

- Com o desgaste reduzido não há mais a tendência de quebra evitando ocorrer perdas significativas;

- Eliminação da situação crítica do assento dos anéis de desgaste da carcaça no interior da bomba;

- Redução drástica de corretivas que aconteciam em finais de horários e finais de semana;

- Redução da alocação de recursos auxiliares fora de programação (guindaste/ munck/etc.);

- Redução considerável no número de bombas com quebras constantes;

- Oficina de Subconjuntos passou a atender via planejamento as demandas de montagem e recuperação de carcaças;

- Aumento da disponibilidade física das bombas;

- Aumento do tempo médio entre falhas (MTBF), reduzindo o número de intervenções;

- Redução do tempo médio para reparo em caso de ocorrências de manutenções corretivas (MTTR).

A figura a seguir resume os resultados em dois períodos de amostra onde é possível verificar a evolução do processo para condições de trabalho os quais as bombas foram dimensionadas para operar e os polímeros foram aplicados mesmo quando uma bomba nova era utilizada. 
Research, Society and Development, v. 10, n. 6, e36810615943, 2021

(CC BY 4.0) | ISSN 2525-3409 | DOI: http://dx.doi.org/10.33448/rsd-v10i6.15943

Figura 8. Quadro comparativo KPIs bombas de água recirculada.

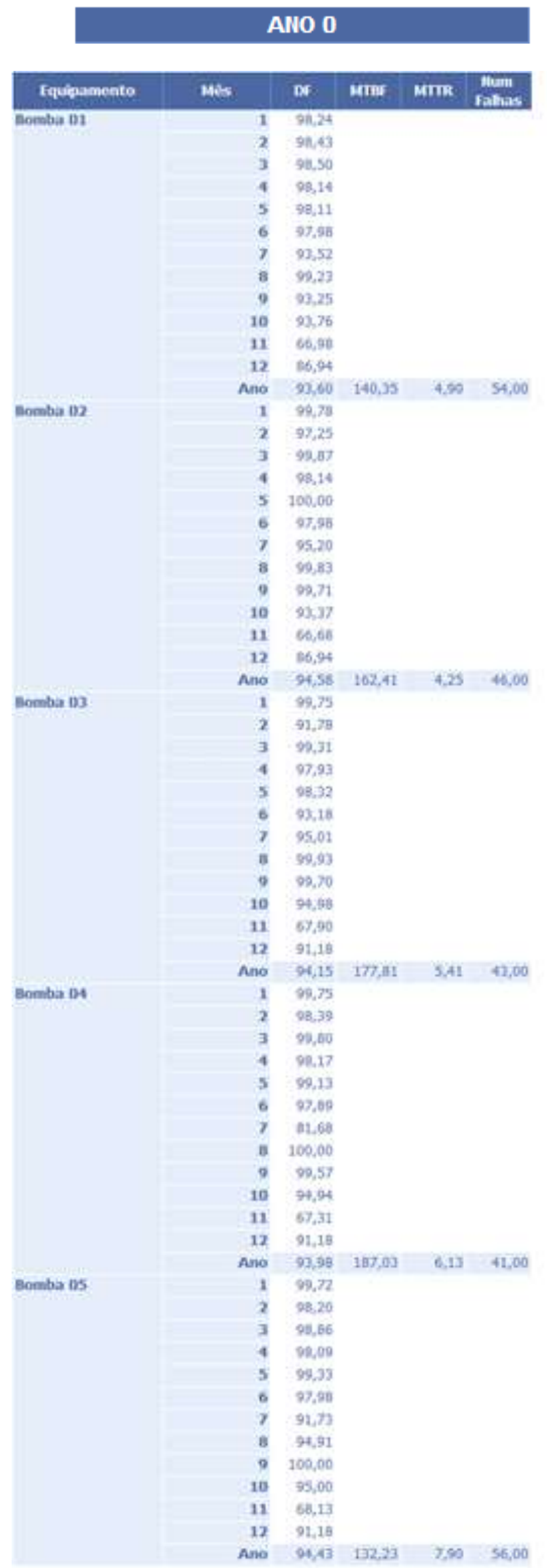

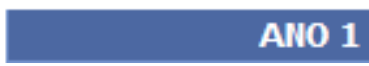

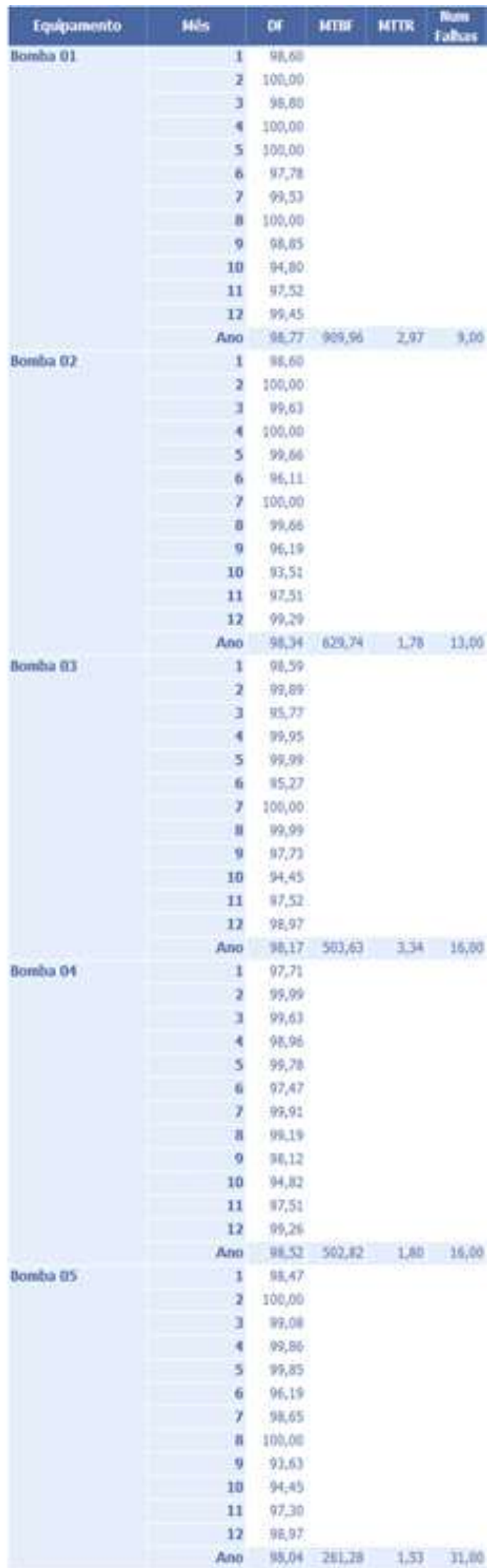

Fonte: Autores. 


\section{Conclusão}

O cenário atual é marcado pela extrema competitividade, ocasionada por profundas alterações das estruturas de mercado. As empresas enfrentam diversas situações ditadas pelos consumidores, pelos clientes, pelos concorrentes e por outros fatores, que dificultam seu crescimento. Esse contexto exige das empresas a redução de custos, a fidelização dos clientes, o aumento do faturamento e a transformação da sua força de trabalho em ferramenta competitiva. De modo geral, as organizações buscam a melhor forma de obter resultados por meio das pessoas e dos processos. Empenhadas em criar formas de obter resultados e abrir caminhos para novas oportunidades no mercado mundial é preciso desenvolver mecanismos que estimulem a capacitação profissional, o comprometimento dos colaboradores e a otimização dos processos e recursos. Tal situação vem provocando também extremas mudanças na forma de trabalho e no nível de exigências dos serviços de manutenção, visto que estes são responsáveis por garantir a continuidade operacional dos processos produtivos. Estas exigências estão diretamente ligadas a todas as áreas de apoio a operação, incluindo às áreas de manutenção e engenharia. Profissionais de alta performance, flexibilidade, inovação, uso de novos materiais e conhecimento técnico elevado são de extrema importância para todas as áreas, principalmente no que se refere à qualidade, confiabilidade, disponibilidade e agilidade dos serviços prestados. É notório que a manutenção não é uma ilha e que depende de outras áreas para executar suas atividades do dia a dia. O custo da produção pode ser impactado por deficiências na reposição de peças de manutenção, mãode-obra parada, equipamentos ociosos, prazos de entregas adiados, perda de clientes, ciclo de vida reduzido, acidentes, baixa performance etc. Dessa forma, o processo de uso de polímeros, foco deste estudo veio em linha com as necessidades aqui relatadas. Processo pode ser entendido, segundo Werkema (1995) como sendo uma combinação dos elementos, equipamentos, insumos, métodos ou procedimentos, condições ambientais, pessoas e informações do processo ou medidas, tendo como objetivo a fabricação de um bem ou o fornecimento de um serviço. Para que seja possível controlar um processo, é necessário identificar os clientes, os produtos demandados e as características da qualidade destes produtos. Para garantir a satisfação destes clientes é necessário transformar estas características da qualidade em grandezas mensuráveis, denominadas itens de controle. Os itens de controle são afetados por várias causas, que medidas e controladas denominam-se itens de verificação (Werkema, 1995). Os itens de controle são estabelecidos sobre os resultados, ou seja, sobre responsabilidades dos gerentes de cada processo. Os itens de verificação são estabelecidos sobre a autoridade, ou seja, nos componentes do processo que podem sofrer influência do gerente para garantir o resultado desejado (Campos, 1998).

No que diz respeito aos objetivos do estudo percebe-se que eles foram atingidos na totalidade. Os resultados corroboram para uma eficácia comprovada nos ensaios de que os polímeros quando aplicados com uma base forte de engenharia de materiais tem a capacidade de aumentar a vida útil de componentes industriais. Essa afirmativa pode ser comprovada na análise dos resultados. Outro ponto a considerar, e muito importante atualmente, são as condições de sustentabilidade. Aumentando o ciclo de vida de um componente, você evita a troca, evita a compra e fabricação de um novo e torna-se possível reduzir a cadeia de suprimentos para aquele item específico. No que diz respeito as variáveis monitoradas os resultados também foram satisfatórios e pode-se notar que cada uma delas é diretamente ou indiretamente impactada pelo uso dos polímeros nos componentes industriais. Durante a análise dos dados foi possível discorrer sobre as mesmas e no referencial teórico foi abordado os conceitos e comportamento de cada uma delas. O estudo hora realizado foi focado na área de mineração e em equipamentos de grande porte e os maiores instalados no mundo atualmente. É de extrema relevância que estudos para indústrias de outras áreas, como metalurgia, química, celulose, siderúrgicas dentre outras possam ser avaliadas e dentro deste contexto avaliar também equipamentos de pequeno porte. Quando se trata de indústrias de outras áreas e equipamentos de portes diferentes (médio e pequeno), pode-se entender que estudos possam levar a ganhos de escala e volume, fatores limitantes da pesquisa em questão. Sugere-se então que devido às limitações de tempo, custos, dados técnicos e outros 
fatores é relevante que novas pesquisas possam entrar a fundo no tema buscando diversificar as áreas e o porte dos equipamentos. Para Geitner (2015) é possível atingir altas taxas de performance a partir de ativos com manutenções de excelência. Para Hernández (2003) é necessário investigar a fundo cada falha e ou problema de forma a evitar a repetição e comprometer o resultado hora alcançado. Estes fatores limitantes não tiram a relevância do trabalho realizado, com base nas premissas e escopo elaborado, e não minimiza os ganhos auferidos na implantação dele. Fazer da manutenção uma área cada vez mais confiável e segura, com custos cada vez menores e ciclo de vida dos ativos cada vez maiores já é uma realidade em muitas plantas de mineração e não temos dúvidas que a pesquisa corrobora com estas afirmativas.

A nova ordem mundial impôs às empresas, uma modificação nos seus processos de produção e consequentemente uma redução de custos e melhor eficiência na gestão de ativos. O objetivo principal é tornar a empresa mais competitiva tendo em vista as novas exigências do mercado mundial. Neste contexto todas as etapas dos processos produtivos devem ter alta produtividade, custos reduzidos e resultados satisfatórios. Em divulgações do Departamento Nacional de Pesquisa Mineral DNPM (2019) percebe-se uma forte mudança na forma de "minerar" para os próximos anos. Vale ressaltar que o aumento na competitividade e a redução de custos estão diretamente atrelados à participação efetiva de cada empregado na melhoria da sua tarefa, na otimização dos tempos e na busca da melhoria contínua, além de práticas que busquem uma manutenção de excelência. Este estudo procurou identificar como a aplicação da engenharia de materiais pode aumentar a vida útil de componentes industriais de forma a mapear os tipos de falhas que ocorrem nos equipamentos industriais, identificar, conceituar e mapear as aplicações e processamento de ligas metálicas, conceituar, classificar e identificar aplicações de polímeros para aumento de vida útil de ativos, executar testes em processos industriais de forma a comprovar as teorias, testar e validar os objetivos da pesquisa e apresentar o caso de sucesso implementado. A interpretação dos resultados da análise e das conclusões permitiram a visualização de uma situação positiva com o uso dos polímeros e uma visualização de que existe um universo de oportunidades ainda a serem exploradas. Identificou-se também que existem polímeros ainda não empregados ou empregados de forma incorreta, o que acarreta a degradação do ativo das empresas, impactando diretamente nos resultados do negócio. Foi detectada também uma necessidade de rever os fluxos de forma a torná-los o mais enxuto possível, mais otimizados, reduzindo etapas, necessidades de aprovações e outros eventos considerados sem relevância para o processo de cadastro para testes até a liberação final para aplicação dos polímeros. É imprescindível também que seja feito um estudo de tempos e movimentos de forma a definir prazos para cada etapa do processo, seja manual ou automático, de forma a estar sempre previamente definido que para cada solicitação o tempo de início e fim de ciclo seja previamente conhecido.

\section{Referências}

Ameida, Pedro M. M. da Costa \& Magalhães, Victor Hugo da Silva (2004); Polímeros; $1^{\circ}$ ed. Universidade Fernando Pessoa, Faculdade de Ciência e Tecnologia, Porto.

Callister Júnior, W.D. \& Rethwisch, D.G. (2016). Ciência e engenharia de materiais: uma introdução (9a ed.). Rio de Janeiro: LTC.

Campos, Vicente Falconi. (1998). Gerenciamento da Rotina do Trabalho do Dia-a-Dia. 7. ed. Belo Horizonte: Editora de Desenvolvimento Gerencial, 276 p.

Departamento Nacional de Pesquisa Mineral. (2019). Cobre. Brasília: DNPM. http://www.dnpm.gov.br.

Flory, P. J. (1953). Principles of polymer chemistry. New York: Cornell University Press.

Geitner, F. K. \& Bloch, H. P. (2015). Análise e solução de falhas em sistemas mecânicos (4a ed.). São Paulo: Elsevier-Campus.

Hernández, S. R., Fernández, C. C. \& Baptista, P. (2003). Metodología de la investigación. México: McGraw-Hill.

Lindeburg, M. R. (2013). Fundamentos da engenharia mecânica: teoria e prática. Rio de Janeiro: LTC.

Kantoviscki, R. K. (2011). Estudo bibliográfico sobre polímeros ambientalmente sustentáveis. (Dissertação de mestrado em Engenharia Ambiental). Programa de Pós-graduação em Engenharia de Materiais - UTFPR, Curitiba, PR, Brasil.

Kepner, C. H. \& Tregoe, B. B. (1997). The new rational manager (2a ed.). New Jersey: Princeton. 
Research, Society and Development, v. 10, n. 6, e36810615943, 2021

(CC BY 4.0) | ISSN 2525-3409 | DOI: http://dx.doi.org/10.33448/rsd-v10i6.15943

Mano, E. B. \& Mendes L. C. (1999). Introdução a polímeros (2a ed.). São Paulo: Blucher.

Manrich, S. (2005). Processamento de termoplásticos, notas de estudo de engenharia química. São Paulo: Artliber Editora.

Masters, L.W. (1986). Prediction of service life of building materials and components. Materials and Structures, 19(6), 417-422.

Ministério da Defesa (2017). Inovação em Engenharia de Manutenção ajudará na manutenibilidade de sistemas e materiais de emprego militar. São Paulo: AGSP.

Sampieri at all (2003); Metodología de la Investigación; México: McGraw-Hill.

Shackelford, J. F. (2017). Ciência dos materiais (6a ed.). São Paulo: Pearson.

Werkema, Maria Cristina Catarino (1995). As Ferramentas da Qualidade no Gerenciamento de Processos. Belo Horizonte, Fundação Christiano Ottoni, Escola de Engenharia da UFMG, 128 p.

Revista In the Mine, (2020) $\left(80^{\circ}\right)$. ed: Repensar a Mineração. São Paulo, SP

Revista Brasil Mineral (2021), (2ed,). Investimentos em Mineração, São Paulo, SP 